Article

\title{
Post-Deepwater Horizon Oil Spill Monitoring of Louisiana Salt Marshes Using Landsat Imagery
}

\author{
Yu Mo*, Michael S. Kearney and J. C. Alexis Riter \\ Department of Environmental Science and Technology, University of Maryland, 1426 Animal Sci./ Ag. Engr. \\ Bldg., College Park, MD 20742, USA; kearneym@umd.edu (M.S.K.); ariter99@umd.edu (J.C.A.R.) \\ * Correspondence: moyu@umd.edu; Tel.: +1-301-405-0095; Fax: +1-301-314-9023
}

Academic Editors: Deepak R. Mishra and Prasad S. Thenkabail

Received: 20 March 2017; Accepted: 21 May 2017; Published: 1 June 2017

\begin{abstract}
The Deepwater Horizon oil spill, the second largest marine oil spill in history, contaminated over a thousand kilometers of coastline in the Louisiana salt marshes and seriously threatened this valuable ecosystem. Measuring the impacts of the oil spill over the large and complex coast calls for the application of remote sensing techniques. This study develops a method for post-Deepwater Horizon oil spill monitoring of the damaged marsh vegetation using Landsat imagery. This study utilizes 10 years of Landsat data, from 2005 to 2014, to examine the longevity of the oil spill's impacts on the marsh vegetation. AVIRIS data collected between 2010 and 2012 are used to validate the Landsat results. Landsat imagery documents the significant effect of oiling on the Normalized Difference Vegetation Index (NDVI) of the marsh vegetation in 2010 and $2011(p<0.01$ in both cases). These results are corroborated by the AVIRIS data, which recorded the most severe impact in May 2011 followed by progressive recovery in October 2011 and October 2012. The Landsat imagery, combined with relevant environmental information and appropriate statistical tools, provides a robust and low-cost method for long-term post-oil spill monitoring of the marshes, revealing that the major aboveground impacts (at $30 \mathrm{~m}$ scale) of the Deepwater Horizon oil spill on Louisiana salt marshes lasted for two years. The method presented is applicable for other hazardous events whenever pre-event referencing and long-term post-event monitoring are desired, thereby offering an effective and economical tool for disaster management.
\end{abstract}

Keywords: Deepwater Horizon oil spill; salt marshes; Louisiana; Landsat; AVIRIS; NDVI

\section{Introduction}

The 2010 Deepwater Horizon oil spill, also known as the Gulf of Mexico oil spill or the Macondo oil spill, is the second largest marine oil spill in history. The Deepwater Horizon oil rig exploded on 20 April 2010 and discharged 780,000 $\mathrm{m}^{3}$ oil into the northern Gulf of Mexico over 87 days [1,2]. This oil, transported by ocean circulation and Stokes drift, contaminated many of the coastal and marine ecosystems in the Gulf [3]. Salt marshes in Louisiana, highly valuable ecosystems that support commercial activities such as fisheries and perform ecological functions such as storm surge attenuation, water purification, and biodiversity conservation, are among the most severely impacted ecosystems. Oil from the Deepwater Horizon drilling rig was found on over a thousand kilometers of coastline in Louisiana in the months following the oil spill [4], extending up to 10-40 $\mathrm{m}$ into the marshes from the shoreline [5-8] and affecting the marshes' above- and belowground biomass, soil microbial activity and nutrient cycling, and shoreline stability [9-12].

Assessing the extent of the oil contamination in terms of space and time over a large and complex coast is very challenging for field studies due to logistical and financial restrictions, and calls for the application of remote sensing techniques. Despite the inherent problems in the application of remote sensing on coastal marshes, the influence of tides and waves on water levels [13-16], remote sensing 
has proven capable of assessing oil contamination. Airborne sensors with high spatial resolution and spectral sensitivity such as AVIRIS and UAVSAR have successfully determined the spatial extent of the oil exposure $[5,8,17]$. However, given the high operational cost and limited data availability of airborne sensors, their use by a wide range of potential investigators is restricted and their application in routine post-oil spill monitoring is not economically feasible.

This study presents a low-cost alternative for post-oil spill monitoring for the damaged marsh vegetation using the Landsat series sensors (i.e., Thematic Mapper, TM; Enhanced Thematic Mapper Plus, ETM+; and Operational Land Imager, OLI). These sensors provide an archive of the marshes going back to 1984, allowing the establishment of a pre-event reference and a long-term post-event monitoring record. The $30 \mathrm{~m}$ spatial resolution of the Landsat data provides sufficient resolution for detecting oil impacts on coastal marsh plants [18]. Moreover, by offering free data, the Landsat program has developed a substantial base of users applying these data to coastal environments. This study uses 10 years of Landsat imagery, from 2005 to 2014, to create a continuous record for pre-oil spill referencing and post-oil spill monitoring to examine the longevity of impacts of the Deepwater Horizon oil spill on Louisiana salt marshes. AVIRIS data collected between 2010 and 2012 are used to validate the Landsat results.

\section{Methods}

\subsection{Study Area}

The exploded Deepwater Horizon oil rig was located $93 \mathrm{~km}$ southeast of the Mississippi River Delta (Figure 1A; Video S1). This study examined impacts of oiling on the salt marshes along the coastlines in the Barataria Bay of southeastern Louisiana, one of the areas most severely impacted by the Deepwater Horizon oil spill. The salt marshes have soil salinity of $>10 \mathrm{ppt}$; are microtidal $(\leq 0.5 \mathrm{~m}$ mean tidal range); and are dominated by Juncus roemerianus and Spartina alterniflora.

The oiling condition of the marsh shorelines was identified using results from the Shoreline Cleanup Assessment Technique (SCAT) ground surveys undertaken in 2010 [19]. The SCAT surveys classified the coastlines into five categories: no oil observed, very light, light, moderate, and heavy oil. The results of five surveys done on 25 June, 12, 15, and 22 July, and 3 August 2010 were incorporated to determine the two extreme cases: shorelines that were consistently found to be heavily oiled in all the five surveys and shorelines that consistently had no field evidence of oil exposure. The two study sites, heavily oiled and non-oiled (Figure 1B), were selected because they are in close proximity and contain target coastlines (i.e., shoreline always classified as heavily oiled or non-oiled in the five surveys) of similar size (approximately 500 Landsat pixels, $15 \mathrm{~km}$ each, Figure 2).

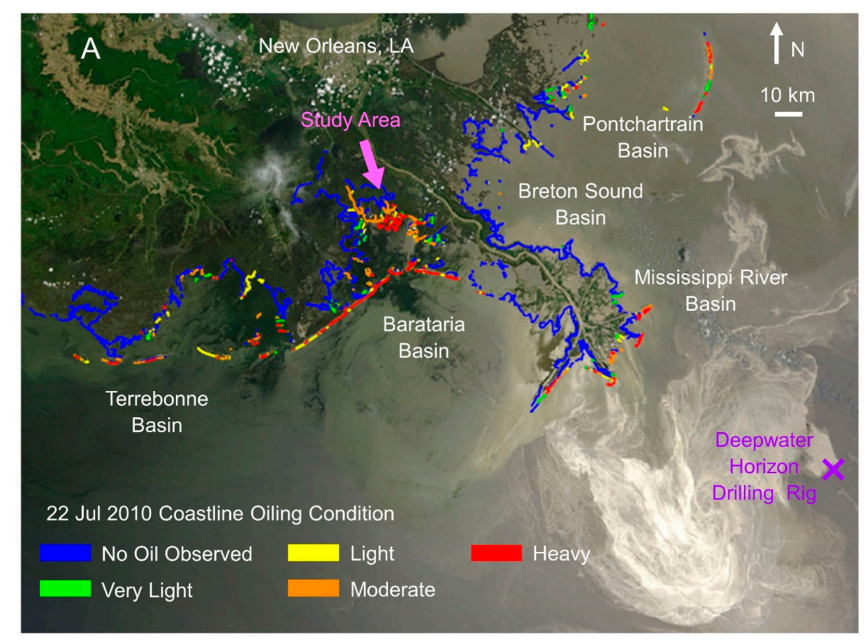

Figure 1. Cont. 


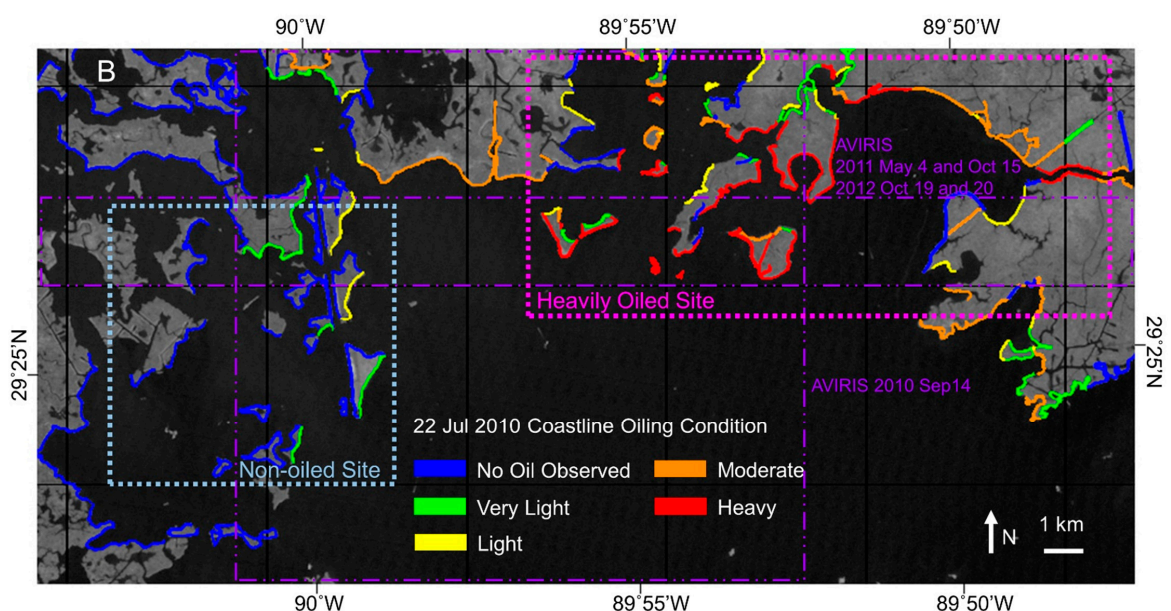

Figure 1. (A) Location of the Deepwater Horizon drilling rig and the study area (magenta arrow). Base map is a MODIS TERRA image of southeastern Louisiana taken on 24 May 2010. (B) Enlarged map of the study area showing the heavily oiled site (sea blue box), the non-oiled site (magenta box), and the footprints of the AVIRIS data sets (purple boxes). Coastlines are classified into five categories based on the Shoreline Cleanup Assessment Technique ground surveys done on 22 July 2010: no oil observed (blue lines), very light (green lines), light (yellow lines), moderate (orange lines), and heavy (red lines) oil.

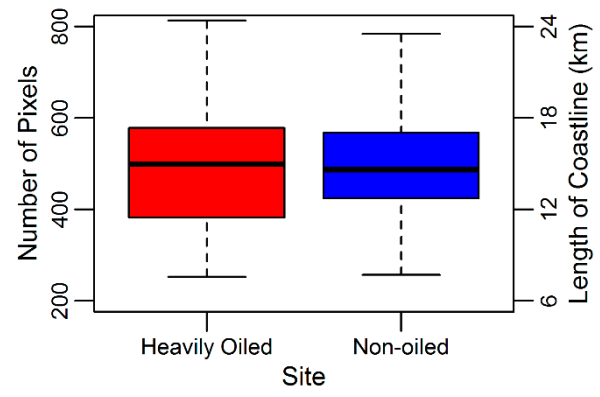

Figure 2. Number of marsh pixels at the target coastlines in the heavily oiled site and the non-oiled site from all sampling dates. The median values are indicated by the box center lines, the first and third quartiles by the box outlines, and the maximum and minimum values by the whiskers.

\subsection{Landsat and AVIRIS Data Sets}

The Landsat Climate Data Record (CDR) was downloaded from the USGS Earth Explorer website [20]. We acquired 10 years of Landsat data from 2005 to 2014, spanning five years before the Deepwater Horizon oil spill to four years after (Figure 3). There were 20, 16, 11, 16, 17, 14, 18, 7, 11, and 14 images used from 2005 to 2014, respectively-a total of 144 images. The imagery came from Landsat 5 TM, Landsat 7 ETM+, and Landsat 8 OLI (Path 22 Row 40; $30 \mathrm{~m}$ spatial resolution).

Because the Landsat 5 was decommissioned in 2011 and the Landsat 8 was not launched until 2013, the 2012 record is exclusively based on the Scan Line Corrector (SLC)-off Landsat 7 data. The SLC on the Landsat 7-which was designed to compensate the forward motion of Landsat 7—failed in May 2003. The line of sight of the SLC-off Landsat 7 then traces a zig-zag pattern, instead of the parallel pattern of the SLC-on Landsat 7, along the satellite ground track, resulting in duplicated areas and gap areas. Hence, the "anomalous data" collected by the SLC-off Landsat 7 contain missing data visible as gaps. However, more than $75 \%$ of the image pixels remain in the anomalous data, and retain the radiometric and geometric precision of the non-anomalous Landsat 7 data [21]. We consider that the SLC-off Landsat 7 data retain their usability in this study, because our analysis doesn't depend on the complete information over the study area [21]. This study did not perform any gap-filling, and only used the remaining pixels 
on the SLC-off Landsat 7 data to assess the vegetation conditions of the target coastlines: we average the information of all the remaining marsh pixels at the target coastlines for each study site in each data set. To ensure that the data in 2012 were comparable to the data in the other years, we only used SLC-off Landsat 7 images that have similar numbers of marsh pixels over the target coastlines as the images of the other sampling years: at least 250 marsh pixels in the target coastlines in each study site after masking out the data gaps, cloud, cloud shadow, and water pixels (Figure 2).

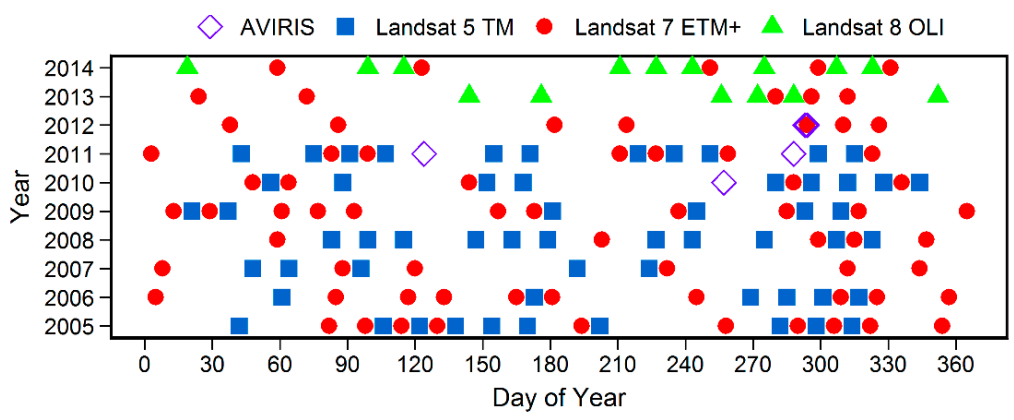

Figure 3. The sampling dates of imagery used in this study from 2005 from 2014 in Julian Day of Year: Landsat 5 Thematic Mapper (TM; blue squares), Landsat 7 Enhanced Thematic Mapper Plus (ETM+; red circles), Landsat 8 Operational Land Imager (OLI; green triangles), and AVIRIS (purple diamonds). The images and their metadata are publicly available through the Gulf of Mexico Research Initiative Information and Data Cooperative (GRIIDC) at https:/ / data.gulfresearchinitiative.org.

AVIRIS data were downloaded from the Jet Propulsion Laboratory website [22]. The data were collected after the Deepwater Horizon oil spill in 2010, 2011, and 2012 (Figure 3). There was one data set from 2010, and two each from 2011 and 2012. The flight lines of AVIRIS, as for all airborne sensors, seldom exactly follow the same course for reasons as simple as the vagaries of wind direction and speed. This study uses data sets whose flight lines transverse at least part of both the heavily oiled site and the non-oiled site (Figure 1B). The AVIRIS data have a spatial resolution of around $3 \mathrm{~m}$. The error in estimating the mean NDVI, as percentage standard deviation, of the AVIRIS data was calculated using the two 2012 October data sets (19 October and 20 October), as they are the only replicate measurements collected within a month.

We processed the remote sensing data sets using ENVI 4.8 and IDL 8.2 software (Exelis, McLean, VA, USA). Normalized Difference Vegetation Index (NDVI) of salt marshes strongly correlates with their aboveground biomass ( $\mathrm{R}^{2}$ 0.7-0.8) [23-25], hence it is used to assess the conditions of the marsh vegetation. NDVI values were calculated from surface reflectance, and those of the interested area were extracted (Figure 4). NDVI was calculated from the surface reflectance $(\rho)$ of the red and near infrared (NIR) bands: NDVI $=\left(\rho_{\text {NIR band }}-\rho_{\text {red band }}\right) /\left(\rho_{\text {NIR band }}+\rho_{\text {red band }}\right)$. The red and NIR bands for Landsat 5 TM and Landsat 7 ETM+ data were Band 3 (626-693 and 631-692 nm, respectively) and Band 4 (776-904 and 772-898 nm, respectively), for Landsat 8 OLI data were Band 4 (630-680 nm) and Band 5 (845-885 nm), and for AVIRIS data were $\rho_{648 \mathrm{~nm}}$ and $\rho_{860 \mathrm{~nm}}$.

For the Landsat data sets, only information from the marsh pixels at the target coastlines (one pixel, $30 \mathrm{~m}$ width) was extracted. The pixels of clouds, cloud shadows, water, and the SLC-off Landsat 7 data gaps were masked out using the $C$ version of the Function of Mask (CFMask) provided with the Landsat CDR. The CFMask is customized for each Landsat image, accounting for the specific cloud and water level conditions at the time of data collection. The number of marsh pixels in each data set varied due to the different cloud and water level conditions, and we only use images have at least 250 marsh pixels at the target coastlines in each study site after masking out the SLC-off Landsat 7 data gap, cloud, cloud shadow, and water pixels. An average of about 500 pixels per image per site was analyzed across the suite of 144 images in this study, with the number of marsh pixels for each site in each image fluctuating from 250 to 800 (Figure 2). For the AVIRIS data sets, zones of different 
widths (i.e., 3, 10, and $30 \mathrm{~m}$ ) next to the shoreline were created, and NDVI values were extracted from each zone. Information from the $30 \mathrm{~m}$ zone was most comparable to the Landsat data, and information from the 3 and $10 \mathrm{~m}$ zones was used to examine the oil impacts at finer scales. The water pixels in the AVIRIS data were masked out using NDVI thresholds.

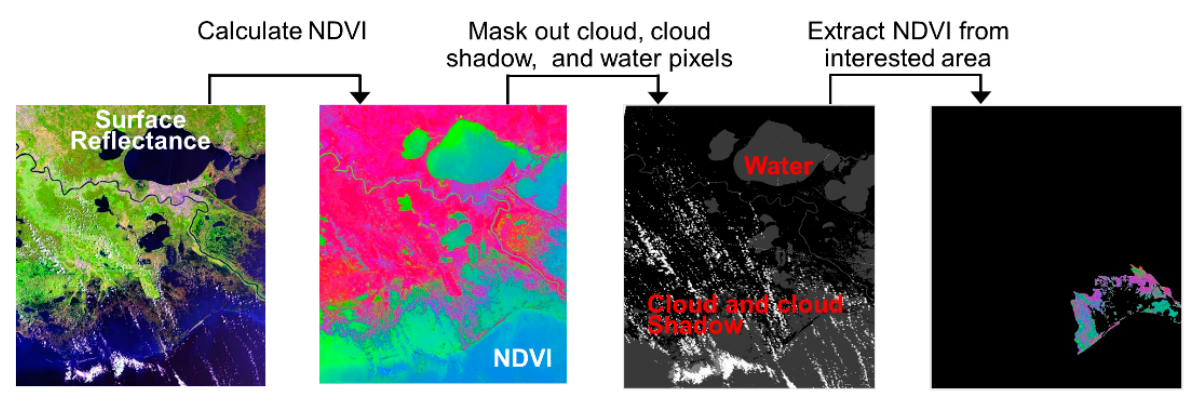

Figure 4. Flowchart of the processing of the Landsat and AVIRIS data in this study (Normalized Different Vegetation Index; NDVI).

\subsection{Climatic (Drought and Tropical Storms) and Water Levels Information}

During the period from 2005 to 2014, the study area experienced different climatic events such as hurricane, i.e., the Category 1 Hurricane Cindy, the Category 3 Hurricane Katrina, and the Category 3 Hurricane Rita in 2005, the Category 2 Hurricane Gustav in 2008, the Tropical Storm Bonnie in 2010, and the Category 1 Hurricane Isaac in 2012; and drought, i.e., severe drought based on the Palmer Drought Severity Index (PDSI) in 2006 and 2011 [26,27]. The negative impacts of hurricane and drought on Louisiana coastal wetlands and their NDVI are well documented [28-30]. Fluctuation in water levels due to tides and winds in coastal marshes can alter the NDVI values of the marshes [13-15]. We addressed this possible source of error by including water level information at the time of satellite data collection into our analysis using the Grand Isle tide gauge (\#8761724) record [31]. The Grand Isle tidal gauge station is approximately $26 \mathrm{~km}$ away from the study area. As it has the only continuous tidal archive over the past few decades for this area in the Louisiana coast, it provides the best information on the water levels.

\subsection{ANCOVA Analysis}

The effects of oiling, annual growth cycle, and water level on the NDVI values of the marshes were analyzed and differentiated using analysis of covariance (ANCOVA) in SAS 9.4 software (SAS Institute, Cary, NC, USA). The heavily oiled site and the non-oiled site were considered as two observational units. One average value was calculated from NDVI values of all pixels in each observational unit for each data set (date). As this study used images year-round, the annual growth cycle of the marshes also affects their seasonal NDVI characteristics. The effects of the annual growth cycle were approximately represented by a second-degree parabola, i.e., effects of Julian Day of Year (DOY) and DOY $\times$ DOY, and tested. It should be noted that the patterns of annual growth cycles of the marshes also reflect impact of major climatic events, which means the effect of annual growth cycle was commingled with the impacts of the effect of the climatic events. The AVIRIS data were interpreted mainly through graphing due to limited sampling dates.

\section{Results}

\subsection{Landsat}

\subsubsection{Oiling Effects}

NDVI values of the target coastlines in the heavily oiled site and the non-oiled site from 2005 to 2014 were extracted (Table A1). Not surprisingly, no oiling effect was detected in years 2005-2009, 
the reference years before the oil spill (Table 1). In 2010, the year of the Deepwater Horizon oil spill, the NDVI values of marshes in the heavily oiled site were significantly lower than those in the non-oiled site $(p<0.01)$, and this phenomenon continued through the drought year of $2011(p<0.01$, Figure 5). Since 2012, the oiling effect was no longer significant. These results suggest that the oiling had a coast-wide impact on the marsh vegetation at the Landsat $30 \mathrm{~m}$ scale for two years. However, it is possible that the oiling was still affecting the marsh vegetation at a finer scale after two years, or in ways that were not reflected by NDVI such as toxic residues in the soil.
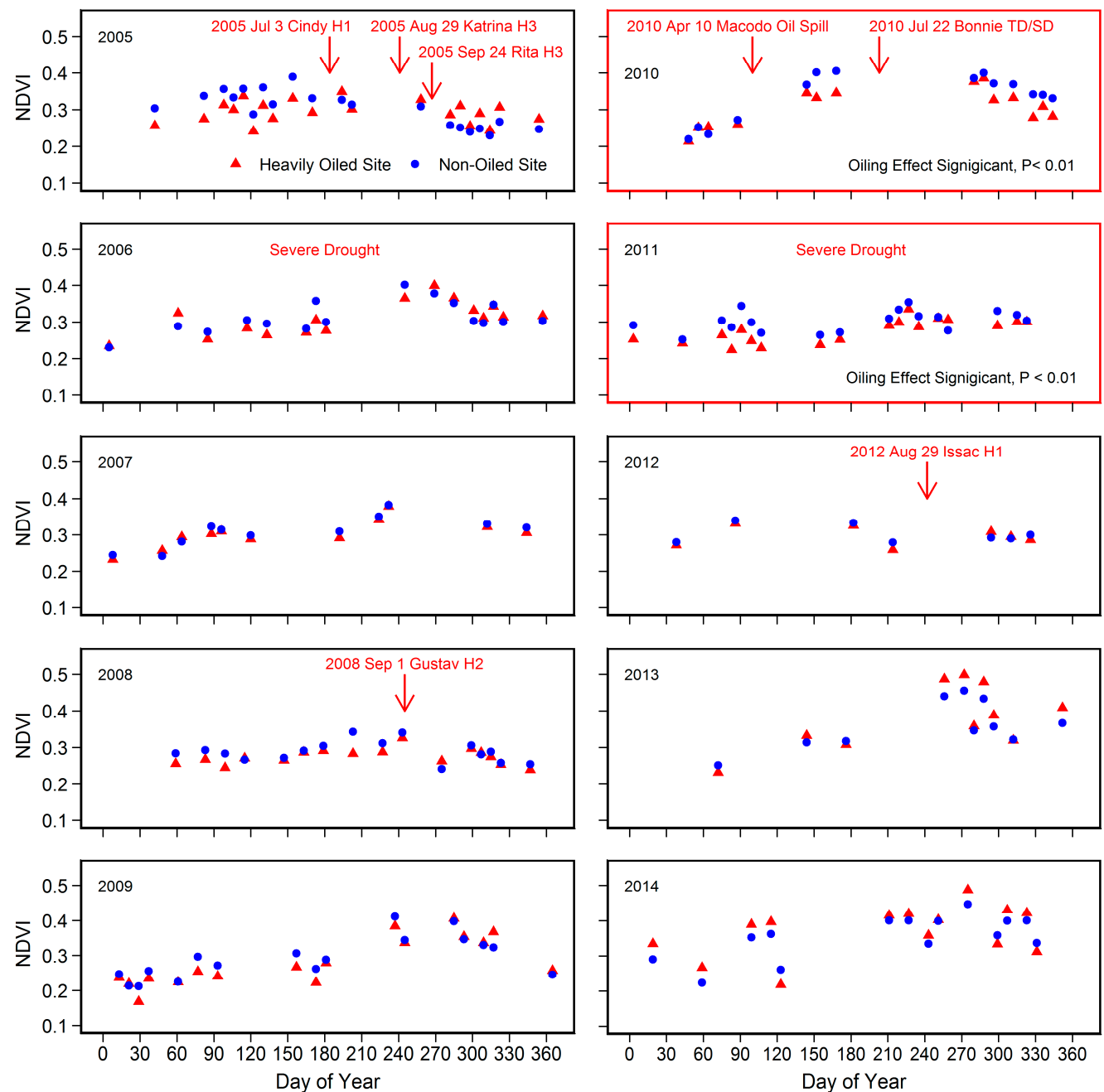

Figure 5. Landsat-derived NDVI of marshes along the target shorelines (30 m width) in the heavily oiled site (red triangles) and the non-oiled site (blue circles) from 2005 to 2014 . The years showing significant oiling impact are highlighted with red frames. The oil spill, hurricane, and drought events during the period are indicated in red.

Table 1. Results of the analysis of covariance (ANCOVA) from 2005 to 2014 ( $p \leq 0.05$ ). (Day of Year; DOY).

\begin{tabular}{|c|c|c|c|c|c|c|c|c|c|c|c|}
\hline \multirow{2}{*}{\multicolumn{2}{|c|}{ Effect }} & \multicolumn{10}{|c|}{$\operatorname{Pr}>F$} \\
\hline & & 2005 & 2006 & 2007 & 2008 & 2009 & 2010 & 2011 & 2012 & 2013 & 2014 \\
\hline \multicolumn{2}{|c|}{ Oiling } & 0.36 & 0.77 & 0.48 & 0.06 & 0.48 & $<0.01 *$ & $<0.01 *$ & 0.72 & 0.39 & 0.41 \\
\hline \multirow{2}{*}{ Annual Growth } & DOY & 0.14 & $0.03 *$ & $<0.01$ * & 0.04 * & $<0.01$ * & $<0.01 *$ & 0.11 & 0.28 & 0.87 & 0.12 \\
\hline & DOY $\times$ DOY & 0.08 & 0.14 & $0.05 *$ & 0.06 & $0.01 *$ & $<0.01$ * & 0.28 & 0.26 & 0.73 & 0.24 \\
\hline \multicolumn{2}{|c|}{ Water level } & 0.95 & 0.99 & 0.71 & 0.21 & 0.11 & 0.21 & 0.18 & 0.45 & 0.10 & 0.66 \\
\hline
\end{tabular}




\subsubsection{Effect of Annual Growth and Water Level}

The effect of the annual growth cycle of the marshes were significant in 2007, 2009 and 2010, but not in 2005, 2006, 2008, and 2011-2014 (Table 1). The NDVI of salt marshes in southeast Louisiana generally peaks from July to August at about 0.45 [29,32]; and the NDVI patterns in 2007, 2009, and 2010 fit with this trend. The annual growth cycle of the marshes may be suppressed by hurricanes such as Cindy, Katrina, and Rita in 2005, Gustav in 2008, and Isaac in 2012, and the severe drought in 2006 and 2011 (Figure 5). These results show that there are multiple factors impacting the annual growth of the marshes, and thus the NDVI of the marshes. The marshes showed noticeable growth in 2013 and 2014, especially over the second half of the years, yet the effect of annual growth was not significant in these two years. This may occur because the quadratic function used to represent the annual growth of the marshes was not applicable in these years. Effect from water level was not significant in all the years, suggesting that this was not an important factor impacting the NDVI values of the marshes at the target coastlines in images used in this study.

\subsection{AVIRIS}

Clear differences exist in NDVI values for the heavily oiled site and the non-oiled site in all AVIRIS data sets collected after the Deepwater Horizon Oil Spill from 2010 to 2012 (Figure 6). The greatest impact was found in the data collected in May 2011, followed by ongoing recovery shown in data collected in October 2011 and October 2012. Although the difference between the mean NDVI values of the heavily oiled site and the non-oiled site in the 2012 October data set are still apparent, its error bars are quite close, indicating a substantial recovery. The AVIRIS data also reveal various levels of oiling impacts at different spatial scales: the NDVI difference was most pronounced in the narrowest zone ( $3 \mathrm{~m}$ width) adjacent to the shoreline, and smallest in the broadest zone (30 $\mathrm{m}$ width). This result is expected as the shorelines were the areas exposed to greatest oiling [7].

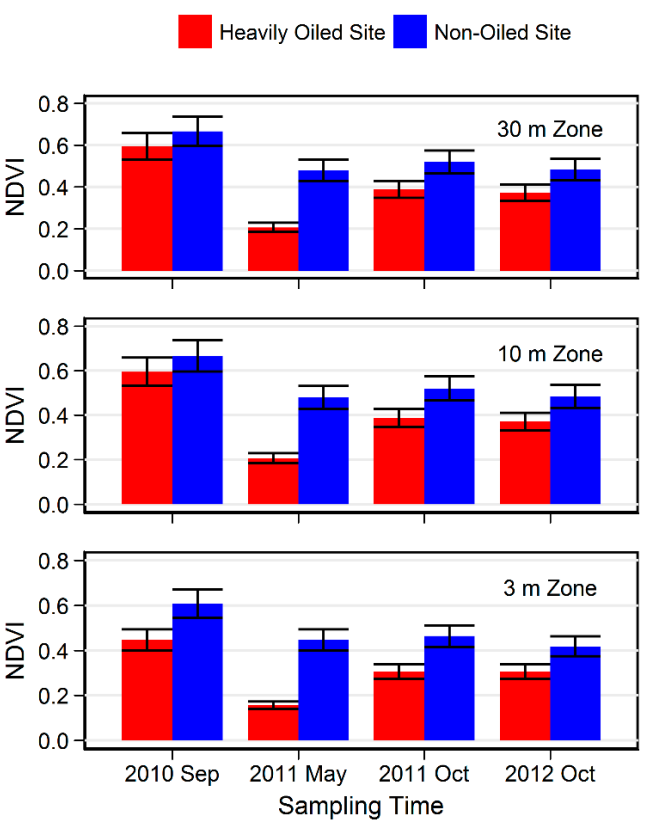

Figure 6. AVIRIS-derived NDVI in 2010-2012 of marshes in the 3, 10, and $30 \mathrm{~m}$ zones next to the target shorelines in the heavily oiled site (red) and the non-oiled site (blue). 


\section{Discussion}

\subsection{Impact of Oil Exposure on the Marsh Vegetation}

Oil contamination in the littoral environment in Louisiana, including Barataria Bay, has been ongoing for many years from a variety of sources (e.g., leaking abandoned wells and pipelines) [33]. Small-scale and local oiling of the marshes in the study area is likely to have occurred prior to the Deepwater Horizon spill. However, the lack of a distinct oil signal in 2005-2009 shows that the marshes' conditions in the heavily oiled and non-oiled sites were comparable before the Deepwater Horizon oil spill (at least at the Landsat $30 \mathrm{~m}$ scale).

The Landsat data show significant oiling effects on the mashes in 2010 and 2011, the year of and the year after the Deepwater Horizon oil spill, which is consistent with results from the AVIRIS data, the PolSAR data [34,35], and field observations [9]. The comparison between the heavily oiled site and the non-oiled site performed in this study is based on the greatest contrast in oiling conditions, and thus, represents the worst scenario of oiling damage on the marshes. We conclude that the marsh vegetation sustained substantial damage from the oil exposure at the scale resolvable by Landsat for two years. It should be noted that the longevity of the damage on the marshes subjected to less severe oiling, i.e., moderate, light, and very light, is still unknown. However, we expect the longevity of the damage on the marshes subjected to moderate, light, and very light oiling to be shorter than two years, because the damage on these marshes should be less severe than the damage on the marshes subjected to heavy oiling. In addition, this study focused on the damaged vegetation adjacent to the shoreline that was not substantially eroded since 2010. Marsh vegetation along shoreline that substantially retreated due to the oiling and 2012 Hurricane Isaac [36,37] were excluded from the results.

The decreases in NDVI values were likely to result from changes in the reflectance characteristics of the plant surface due to coverage of the green aboveground biomass (leaves and stems) by the dark crude oil, and from decreased aboveground biomass due to oil contamination $[9,10]$. Because Landsat-derived NDVI offers measurements of the aboveground biomass and not of the plant physiological functions, our results were not able to further the discussion of the mechanism of the oil impact.

It is possible that the oil of Deepwater Horizon still affects the marshes after two years, but in ways not detectable by measuring the aboveground biomass using the Landsat imagery. The oil residues were still found in the marsh substrates after two years and might have degraded or transformed into different compounds [38,39]. Further study needs to be done to investigate whether the oil residues will impair the marsh vegetation again in the future. It is also possible that the oiling impacts at smaller scales (e.g., $3 \mathrm{~m}$ width zone from the shoreline) lasted for more than two years, as the AVIRIS data show that the NDVI difference was more pronounced in the narrow zone ( $3 \mathrm{~m}$ width) than in the broad zone (30 $\mathrm{m}$ width). Unfortunately, statistical tests of the finer-scale impacts using ANCOVA on the AVIRIS data were not possible due to limited data availability.

\subsection{Climatic Impacts on the Marshes Annual Growth}

The NDVI patterns in 2007, 2009, and 2010 peaked at about 0.45 in July to August, which follow the general trend of the annual growth dynamics of salt marshes in southeast Louisiana $[29,32]$. In 2005, 2008, and 2012, the annual growth of the marshes was likely to be suppressed by hurricanes Cindy, Katrina, and Rita, Gustav, and Isaac, respectively. In 2008, it is shown that the NDVI of the marshes quickly drop immediately following Hurricane Gustav. Certainly, marshes along coastlines, just as those in our target coastlines, are susceptible to the winds and storm surges brought by hurricanes. Therefore, the insignificance of the annual growth cycle in 2005, 2008, and 2012 is likely to reflect the impacts of the hurricanes. The low NDVI in 2006 and 2011, especially over the summer months of June and July, may largely reflect the severe drought conditions in the southeastern Louisiana during these years [29]. Drought conditions in salt marshes may be manifested as increased stress in water potential as well as increase in hydrogen sulfide contents, both of which are inimical to maintenance of the vigor 
of the marsh plants $[29,40]$. Because the experimental design (i.e., site selection) of this study is planned to examine the impacts of the Deepwater Horizon oil spill, this study is not able to provide statistical analysis of the impacts of other events such as droughts and hurricanes. The impacts of hurricane and drought can only be investigated with more confidence in further studies with experimental designs planned for examining these events.

\subsection{Landsat for Post-Event Monitoring}

This study demonstrates that Landsat imagery, combined with relevant environmental information and appropriate statistical tools, can provide reliable data for large-scale monitoring of the impacts of the Deepwater Horizon oil spill on the damaged marsh vegetation. Landsat data have several advantages compared to other satellite data. The Landsat data are free, and thus accessible for a wide range of investigators. The $30 \mathrm{~m}$ spatial resolution of the Landsat sensors (i.e., TM, ETM+, and OLI)—which is much less than the other satellite sensors such as the $250 \mathrm{~m}$ for MODIS and the $1.1 \mathrm{~km}$ for AVHRR - is important for researching the highly spatially heterogeneous coastal environment. Moreover, Landsat's continuous data archive allows for assessment of pre-oil spill conditions and routine post-oil spill monitoring. As Landsat has an unrivalled long-term observation record of the Earth that dates to the 1980s and is expected to continue (Landsat 9 is planned to launch in 2023), this method is potentially applicable for post-event monitoring of many other disastrous events, for retrospective studies of extreme events in the past or for real-time monitoring of extreme events in the future.

Certainly, the Landsat multispectral sensors have their limitations: they are most effective in measuring aboveground biomass of the marshes, not in delineating the extent of the oil exposure. Therefore, before applying the Landsat data, this study used the SCAT field data to determine the oiling condition of the study area. Also, since Landsat-derived NDVI only offers measurements of the aboveground biomass, and the aboveground biomass of the marshes is influenced by different environmental conditions, we need to use appropriate statistical tools, such as ANCOVA in this study, to differentiate the impacts of oiling from impacts of other environmental factors.

Some limitations of Landsat may be addressed by using hyperspectral or radar instruments, which offer higher spatial resolution and spectral sensitivity to demarcate more precisely the actual extent of the impacts of the Deepwater Horizon oil spill or other extreme events on the marshes [5,8]. Yet airborne hyperspectral and radar sensors are limited in their use by a wide range of investigators due to their high operational expense and limited data availability, particularly outside of the North America. Spaceborne hyperspectral sensors (e.g., EnMAP, scheduled for launch in 2018) and radar sensors (e.g., TerraSAR-X and TanDem-X, launched in 2007 and 2010, respectively) may be applicable for routine post-event monitoring. But again, the actual data availability in terms of both spatial and temporal coverage and cost for data acquisition of these sensors will determine their applicability for specific events. Nevertheless, the occasional deployment of sensors with high spatial resolution and spectral sensitivity provides validation for the Landsat results and enhances the assessment of finer-scale impacts.

\section{Conclusions}

This study uses 10 years of Landsat data from 2005 to 2014 and three years of AVIRIS data from 2010 to 2012 to examine the longevity of impacts of the Deepwater Horizon oil spill on the salt marshes in the Barataria Bay, LA. We conclude that the major aboveground impacts (at $30 \mathrm{~m}$ scale) of the oil spill on the marsh vegetation lasted for two years, 2010 and 2011 ( $p<0.01$ in both cases). The Landsat imagery, combined with relevant environmental information and appropriate statistical tools, provides a robust and low-cost method for long-term post-oil spill monitoring of the marshes. The method presented is applicable for other hazardous events whenever pre-event referencing and routine post-event monitoring is desired, thereby providing an effective and economical tool for disaster management. 
Supplementary Materials: The following are available online at www.mdpi.com/2072-4292/9/6/547/s1, Looking at the Deepwater Horizon oil spill using multispectral satellite imagery.

Acknowledgments: This research was made possible by a grant from The Gulf of Mexico Research Initiative. Data are publicly available through the Gulf of Mexico Research Initiative Information and Data Cooperative (GRIIDC) at https:/ / data.gulfresearchinitiative.org (doi:10.7266/N75Q4T4F).

Author Contributions: Yu Mo and Michael S. Kearney conceived and designed the experiments; Yu Mo and J. C. Alexis Riter processed and analyzed the data; Yu Mo, Michael S. Kearney, and J. C. Alexis Riter wrote the paper.

Conflicts of Interest: The authors declare no conflict of interest.

\section{Appendix A}

Table A1. Mean Normalized Difference Vegetation Index (NDVI) values and their standard deviation (SD) of the heavily oiled site (HO) and non-oiled site (NO) from the sample dates (Day of Year, or DOY) from 2005 to 2014.

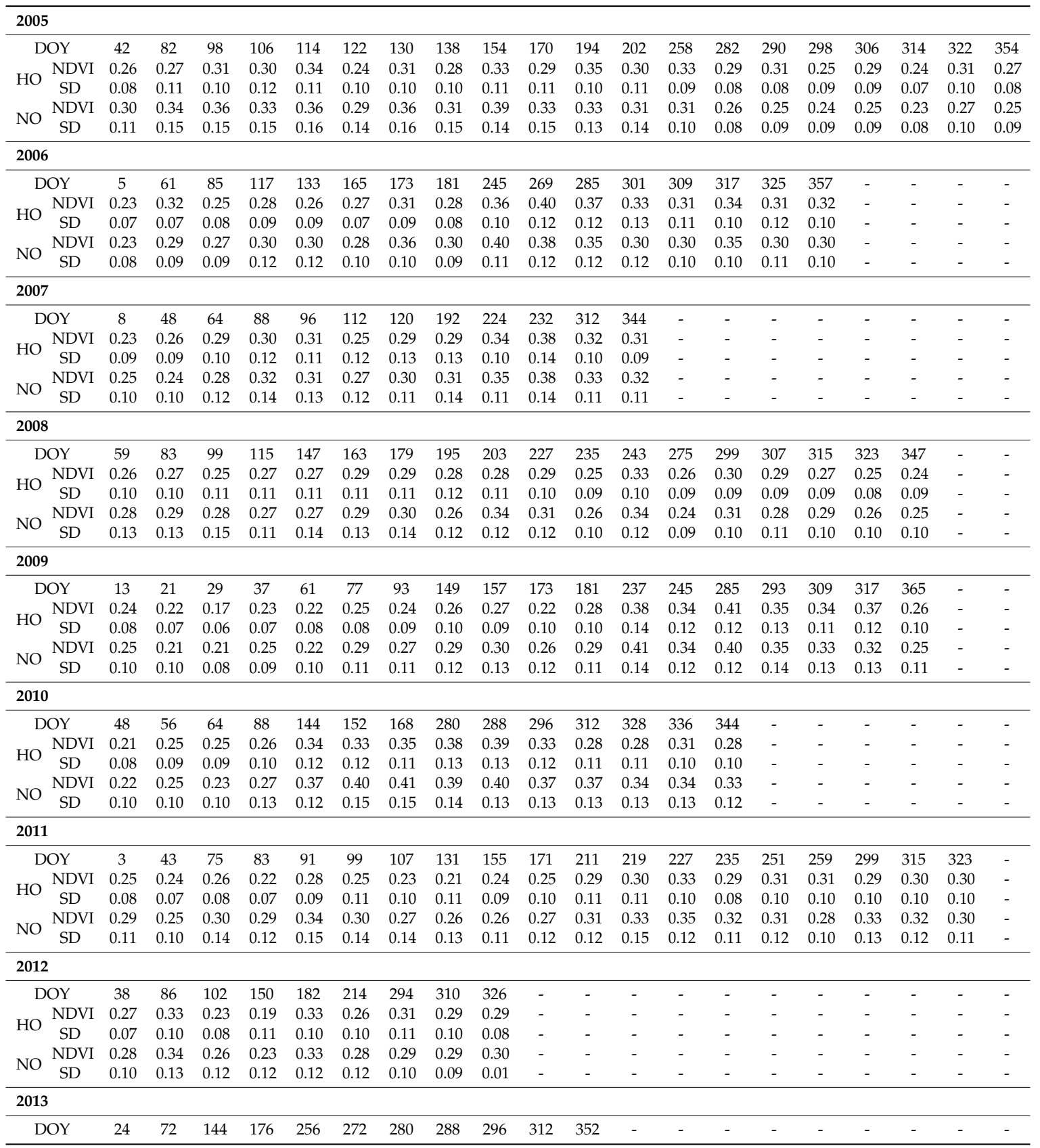


Table A1. Cont.

\begin{tabular}{|c|c|c|c|c|c|c|c|c|c|c|c|c|c|c|c|c|c|c|c|c|c|}
\hline \multirow{2}{*}{$\mathrm{HO}$} & NDVI & 0.27 & 0.23 & 0.33 & 0.31 & 0.49 & 0.50 & 0.36 & 0.48 & 0.39 & 0.32 & 0.41 & - & - & - & - & - & - & - & - & - \\
\hline & $\mathrm{SD}$ & 0.07 & 0.08 & 0.14 & 0.14 & 0.15 & 0.14 & 0.13 & 0.14 & 0.14 & 0.13 & 0.12 & - & - & - & - & - & - & - & - & - \\
\hline $\mathrm{NO}$ & SD & 0.10 & 0.10 & 0.16 & 0.15 & 0.16 & 0.15 & 0.14 & 0.15 & 0.13 & 0.13 & 0.12 & - & - & - & - & - & - & - & - & - \\
\hline \multicolumn{2}{|c|}{ DOY } & 19 & 59 & 99 & 115 & 123 & 211 & 227 & 243 & 251 & 275 & 299 & 307 & 323 & 331 & - & - & - & - & - & - \\
\hline \multirow{2}{*}{$\mathrm{HO}$} & NDVI & 0.33 & 0.27 & 0.39 & 0.40 & 0.22 & 0.42 & 0.42 & 0.36 & 0.40 & 0.49 & 0.33 & 0.43 & 0.42 & 0.31 & - & - & - & - & - & - \\
\hline & $\mathrm{SD}$ & 0.10 & 0.10 & 0.14 & 0.13 & 0.11 & 0.15 & 0.15 & 0.14 & 0.13 & 0.14 & 0.10 & 0.12 & 0.13 & 0.11 & - & - & - & - & - & - \\
\hline $\mathrm{NO}$ & SD & 0.11 & 0.09 & 0.16 & 0.14 & 0.14 & 0.16 & 0.17 & 0.16 & 0.12 & 0.16 & 0.11 & 0.15 & 0.14 & 0.12 & - & - & - & - & - & - \\
\hline
\end{tabular}

\section{References}

1. McNutt, M.; Camilli, R.; Guthrie, G.; Hsieh, P.; Labson, V.; Lehr, B.; Maclay, D.; Ratzel, A.; Sogge, M. Assessment of Flow Rate Estimates for the Deepwater Horizon/Macondo Well Oil Spill; U.S. Department of the Interior: Washington, DC, USA, 2011.

2. Liu, Y.G.; MacFadyen, A.; Ji, Z.G.; Weisberg, R.H. Introduction to monitoring and modeling the deepwater horizon oil spill. In Monitoring and Modeling the Deepwater Horizon Oil Spill: A Record-Breaking Enterprise; American Geophysical Union: Washington, DC, USA, 2011; Volume 195, pp. 1-7.

3. Weisberg, R.H.; Lianyuan, Z.; Liu, Y. On the movement of Deepwater Horizon oil to northern Gulf beaches. Ocean Model. 2017, 111, 81-97. [CrossRef]

4. Nixon, Z.; Zengel, S.; Baker, M.; Steinhoff, M.; Fricano, G.; Rouhani, S.; Michel, J. Shoreline oiling from the Deepwater Horizon oil spill. Mar. Pollut. Bull. 2016, 107, 170-178. [CrossRef] [PubMed]

5. Kokaly, R.F.; Couvillion, B.R.; Holloway, J.M.; Roberts, D.A.; Ustin, S.L.; Peterson, S.H.; Khanna, S.; Piazza, S.C. Spectroscopic remote sensing of the distribution and persistence of oil from the Deepwater Horizon spill in Barataria Bay marshes. Remote Sens. Environ. 2013, 129, 210-230. [CrossRef]

6. Peterson, S.H.; Roberts, D.A.; Beland, M.; Kokaly, R.F.; Ustin, S.L. Oil detection in the coastal marshes of Louisiana using MESMA applied to band subsets of AVIRIS data. Remote Sens. Environ. 2015, 159, 222-231. [CrossRef]

7. Khanna, S.; Santos, M.J.; Ustin, S.L.; Koltunov, A.; Kokaly, R.F.; Roberts, D.A. Detection of salt marsh vegetation stress and recovery after the Deepwater Horizon oil spill in Barataria Bay, Gulf of Mexico using AVIRIS data. PLoS ONE 2013, 8, e78989. [CrossRef] [PubMed]

8. Ramsey, E.; Rangoonwala, A.; Suzuoki, Y.; Jones, C.E. Oil detection in a coastal marsh with polarimetric Synthetic Aperture Radar (SAR). Remote Sens. 2011, 3, 2630-2662. [CrossRef]

9. Silliman, B.R.; van de Koppel, J.; McCoy, M.W.; Diller, J.; Kasozi, G.N.; Earl, K.; Adams, P.N.; Zimmerman, A.R. Degradation and resilience in Louisiana salt marshes after the BP-Deepwater Horizon oil spill. Proc. Natl. Acad. Sci. USA 2012, 109, 11234-11239. [CrossRef] [PubMed]

10. Lin, Q.X.; Mendelssohn, I.A. Impacts and recovery of the Deepwater Horizon oil spill on vegetation structure and function of coastal salt marshes in the northern Gulf of Mexico. Environ. Sci. Technol. 2012, 46, 3737-3743. [CrossRef] [PubMed]

11. Pietroski, J.P.; White, J.R.; DeLaune, R.D. Effects of dispersant used for oil spill remediation on nitrogen cycling in Louisiana coastal salt marsh soil. Chemosphere 2015, 119, 562-567. [CrossRef] [PubMed]

12. McClenachan, G.; Turner, R.E.; Tweel, A.W. Effects of oil on the rate and trajectory of Louisiana marsh shoreline erosion. Environ. Res. Lett. 2013, 8, 044030. [CrossRef]

13. Byrd, K.B.; O'Connell, J.L.; Di Tommaso, S.; Kelly, M. Evaluation of sensor types and environmental controls on mapping biomass of coastal marsh emergent vegetation. Remote Sens. Environ. 2014, 149, 166-180. [CrossRef]

14. Beget, M.E.; Di Bella, C.M. Flooding: The effect of water depth on the spectral response of grass canopies. J. Hydrol. 2007, 335, 285-294. [CrossRef]

15. Kearney, M.S.; Stutzer, D.; Turpie, K.; Stevenson, J.C. The effects of tidal inundation on the reflectance characteristics of coastal marsh vegetation. J. Coast. Res. 2009, 25, 1177-1186. [CrossRef]

16. Turpie, K.R. Explaining the spectral red-edge features of inundated marsh vegetation. J. Coast. Res. 2013, 29, 1111-1117. [CrossRef]

17. Jones, C.E.; Minchew, B.; Holt, B.; Hensley, S. Studies of the Deepwater Horizon oil spill with the UAVSAR radar. In Monitoring and Modeling the Deepwater Horizon Oil Spill: A Record-Breaking Enterprise; American Geophysical Union: Washington, DC, USA, 2011; Volume 195, pp. 33-50. 
18. Mishra, D.R.; Cho, H.J.; Ghosh, S.; Fox, A.; Downs, C.; Merani, P.B.T.; Kirui, P.; Jackson, N.; Mishra, S. Post-spill state of the marsh: Remote estimation of the ecological impact of the Gulf of Mexico oil spill on Louisiana salt marshes. Remote Sens. Environ. 2012, 118, 176-185. [CrossRef]

19. Environmental Response Management Application, Deepwater Horizon Gulf of Mexico, Response, Damage Assessment \& Restoration. Available online: http:/ / gomex.erma.noaa.gov/ (accessed on 15 March 2017).

20. Earth Explorer. Available online: http:/ / earthexplorer.usgs.gov/ (accessed on 15 March 2017).

21. Andrefouet, S.; Bindschadler, R.; Brown de Colstoun, E.C.; Choate, M.; Chomentowski, W.; Christopherson, J.; Doorn, B.; Hall, D.K.; Holifield, C.; Howard, S.; et al. Preliminary Assessment of the Value of Landsat-7 ETM+ Data Following Scan Line Corrector Malfunction; U.S. Geological Survey, EROS Data Center: Sioux Falls, SD, USA, 2003.

22. Airborne Visible/Infrared Imaging Spectrometer. Available online: http://aviris.jpl.nasa.gov/ (accessed on 15 March 2017).

23. Zhang, M.; Ustin, S.L.; Rejmankova, E.; Sanderson, E.W. Monitoring pacific coast salt marshes using remote sensing. Ecol. Appl. 1997, 7, 1039-1053. [CrossRef]

24. Gross, M.F.; Hardisky, M.A.; Wolf, P.L.; Klemas, V. Relationships among Typha biomass, pore water methane, and reflectance in a delaware (U.S.A.) brackish marsh. J. Coast. Res. 1993, 9, 339-355.

25. Gross, M.F.; Hardisky, M.A.; Klemas, V.; Wolf, P.L. Quantification of biomass of the marsh grass Spartina alterniflora Loisel using Landsat Thematic Mapper imagery. Photogramm. Eng. Remote Sens. 1987, 53, 1577-1583.

26. Historical Hurricane Tracks. Available online: https://coast.noaa.gov/hurricanes/ (accessed on 15 March 2017).

27. Historical Palmer Drought Indices. Available online: http://www.ncdc.noaa.gov/temp-and-precip/ drought/historical-palmers / (accessed on 15 March 2017).

28. Alber, M.; Swenson, E.M.; Adamowicz, S.C.; Mendelssohn, I.A. Salt marsh dieback: An overview of recent events in the US. Estuar. Coast. Shelf Sci. 2008, 80, 1-11. [CrossRef]

29. Mo, Y.; Momen, B.; Kearney, M.S. Drought-associated phenological changes of coastal marshes in Louisiana. Ecosphere 2017, 8, e01811. [CrossRef]

30. Kearney, M.S.; Riter, J.C.A.; Turner, R.E. Freshwater river diversions for marsh restoration in Louisiana: Twenty-six years of changing vegetative cover and marsh area. Geophys. Res. Lett. 2011, 38. [CrossRef]

31. Tides and Currents. Available online: http://tidesandcurrents.noaa.gov/waterlevels.html (accessed on 15 March 2017).

32. Mo, Y.; Momen, B.; Kearney, M.S. Quantifying moderate resolution remote sensing phenology of Louisiana coastal marshes. Ecol. Model. 2015, 312, 191-199. [CrossRef]

33. CBSNEWS. 27,000 Abandoned Gulf Oil Wells May Be Leaking. Available online: http://www.cbsnews. com/news/27000-abandoned-gulf-oil-wells-may-be-leaking/ (accessed on 15 March 2017).

34. Ramsey, E.; Rangoonwala, A.; Jones, C.E. Marsh canopy structure changes and the Deepwater Horizon oil spill. Remote Sens. Environ. 2016, 186, 350-357. [CrossRef]

35. Ramsey, E.; Rangoonwala, A.; Jones, C.E. Structural classification of marshes with polarimetric SAR highlighting the temporal mapping of marshes exposed to oil. Remote Sens. 2015, 7, 11295-11321. [CrossRef]

36. Rangoonwala, A.; Jones, C.E.; Ramsey, E. Wetland shoreline recession in the Mississippi River delta from petroleum oiling and cyclonic storms. Geophys. Res. Lett. 2016, 43, 11652-11660. [CrossRef]

37. Turner, R.E.; McClenachan, G.; Tweel, A.W. Islands in the oil: Quantifying salt marsh shoreline erosion after the Deepwater Horizon oiling. Mar. Pollut. Bull. 2016, 110, 316-323. [CrossRef] [PubMed]

38. Pendergraft, M.A.; Rosenheim, B.E. Varying relative degradation rates of oil in different forms and environments revealed by ramped pyrolysis. Environ. Sci. Technol. 2014, 48, 10966-10974. [CrossRef] [PubMed]

39. Turner, R.E.; Overton, E.B.; Meyer, B.M.; Miles, M.S.; Hooper-Bui, L. Changes in the concentration and relative abundance of alkanes and pahs from the Deepwater Horizon oiling of coastal marshes. Mar. Pollut. Bull. 2014, 86, 291-297. [CrossRef] [PubMed]

40. Webb, E.C.; Mendelssohn, I.A.; Wilsey, B.J. Causes for vegetation dieback in a Louisiana salt marsh: A bioassay approach. Aquat. Bot. 1995, 51, 281-289. [CrossRef]

(C) 2017 by the authors. Licensee MDPI, Basel, Switzerland. This article is an open access article distributed under the terms and conditions of the Creative Commons Attribution (CC BY) license (http:/ / creativecommons.org/licenses/by/4.0/). 